Cardiology 2020;145:236-250

DOI: $10.1159 / 000505365$
Received: August 7, 2019

Accepted after revision: December 10, 2019

Published online: March 13, 2020

\title{
Cholesteryl Ester Transfer Protein Inhibitors and Cardiovascular Outcomes: A Systematic Review and Meta-Analysis of Randomized Controlled Trials
}

\author{
Hossein Taheri ${ }^{\mathrm{a}, \mathrm{b}}$ Kristian B. Filion ${ }^{\mathrm{a}-\mathrm{c}}$ Sarah B. Windle ${ }^{\mathrm{a}}$ Pauline Reynier $^{\mathrm{a}}$ \\ Mark J. Eisenberg ${ }^{a-d}$ \\ ${ }^{a}$ Center for Clinical Epidemiology, Lady Davis Institute for Medical Research, Jewish General Hospital/ \\ McGill University, Montreal, QC, Canada; ${ }^{b}$ Department of Medicine, McGill University, Montreal, QC, Canada; \\ 'Department of Epidemiology, Biostatistics and Occupational Health, McGill University, Montreal, QC, Canada; \\ ${ }^{d}$ Division of Cardiology, Jewish General Hospital/McGill University, Montreal, QC, Canada
}

\section{Keywords}

Cholesteryl ester transfer protein inhibitors .

High-density lipoproteins - Low-density lipoproteins .

Cardiovascular events - Systematic review - Meta-analysis

\begin{abstract}
Background: Cholesteryl ester transfer protein (CETP) inhibitors increase serum high-density lipoprotein cholesterol (HDL-c) concentration; however, their impact on cardiovascular outcomes is not clear. This systematic review examines the effect of CETP inhibitors on serum lipid profiles, cardiovascular events, and all-cause mortality. Methods: We searched MEDLINE, Embase, and the Cochrane Library of Clinical Trials for placebo-controlled randomized controlled trials (RCTs) that examined the effect of a CETP inhibitor (dalcetrapib, anacetrapib, evacetrapib, or TA-8995) on all-cause mortality, major adverse cardiovascular events (MACE), or the components of MACE at $\geq 6$ months. Data were pooled using random-effects models. Results: A total of 11 RCTs $(n=62,431)$ were included in our systematic review; 4 examined dalcetrapib $(n=16,612), 6$ anacetrapib $(n=33,682)$, and 1 evacetrapib $(n=12,092)$. Compared to dalcetrapib, ana-
\end{abstract}

cetrapib and evacetrapib were more efficacious at raising HDL-c levels ( 100-130 vs. 30\%). Anacetrapib and evacetrapib also decreased low-density lipoprotein cholesterol (LDL-c) by approximately $30 \%$ while dalcetrapib did not affect the LDL-c level. Overall, CETP inhibitors were not associated with the incidence of MACE (pooled relative risk [RR]: 0.97; 95\% confidence interval [CI]: 0.91-1.04). CETP inhibitors may decrease the risks of nonfatal myocardial infarction (MI) (RR: 0.93; 95\% Cl: 0.87-1.00) and cardiovascular death (RR: $0.92 ; 95 \% \mathrm{Cl}: 0.83-1.01$ ), though these trends did not reach statistical significance. Conclusions: CETP inhibitors are not associated with an increased risk of MACE or all-cause mortality. There is a trend towards small reductions in nonfatal MI and cardiovascular death, though the clinical importance of such reductions is likely modest.

(c) 2020 S. Karger AG, Basel

\section{Introduction}

Cholesteryl ester transfer protein (CETP) inhibitors, including dalcetrapib, evacetrapib, and anacetrapib, are novel agents that have been developed to increase serum karger@karger.com

www.karger.com/crd

Karger
(C) 2020 S. Karger AG, Basel

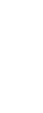

\footnotetext{
Mark J. Eisenberg, MD, MPH

Jewish General Hospital/McGill University

3755 Côte Ste-Catherine Road, Suite H-421.1

Montreal, QC H3T 1E2 (Canada)

mark.eisenberg@mcgill.ca
} 
high-density lipoprotein cholesterol (HDL-c) concentration. These agents increase HDL-c levels by inhibiting an enzyme that catalyzes the exchange of cholesteryl esters and triglycerides between HDL and low-density lipoproteins (LDL). Despite being efficacious at increasing HDL levels, the CETP inhibitors' impact on cardiovascular outcomes remains unclear, particularly as observed benefits could also be related to lowering LDL cholesterol (LDL-c) [1]. Previous trials of other HDL-c-raising medications such as fibrates and niacin have failed to demonstrate that the use of these medications impacts clinical outcomes among patients already taking statins [2]. Optimal HDL-c targets for clinical benefit are unclear, as extremely elevated HDL-c has been associated with increased all-cause mortality [1]. Anacetrapib, notably, is also known to accumulate in adipose tissues in the long-term [1]. With the publication of two large clinical trials of CETP inhibitors, REVEAL and ACCELERATE, there is a need to synthesize the available evidence concerning the efficacy of CETP inhibitors [3, 4]. Therefore, we conducted a systematic review and meta-analysis of randomized controlled trials (RCTs) to assess the effect of CETP inhibitors on cardiovascular outcomes and lipid levels.

\section{Methods}

Our systematic review with meta-analysis, which followed a prespecified protocol, was designed and reported according to the Preferred Reporting Items for Systematic Reviews and Meta-Analyses (PRISMA) guidelines [5].

\section{Search Strategy}

We systematically searched MEDLINE, Embase, and the Cochrane Library of Clinical Trials databases from inception to July 11,2017 , to identify RCTs that assessed the efficacy and safety of CETP inhibitors. Our search strategies (Appendices $1-3)$ were constructed using the drug names of interest: obicetrapib or TA-8995, evacetrapib or LY2484595, dalcetrapib or JTT-705, and anacetrapib or MK-0859. Torcetrapib was excluded from our search since it was no longer under investigation at the time our protocol was written, due to the increased mortality associated with its use [6]. MEDLINE and Embase searches were restricted to RCTs using a modified version of the McMaster RCT hedge [7]. Reference lists of included trials and relevant reviews were scanned to identify additional RCTs not included in the results of our electronic search. Lastly, ClinicalTrials.gov was also searched for RCTs that were registered and completed but not yet published.

\section{Inclusion Criteria}

The title and abstract of all publications identified in our electronic search were screened independently by two reviewers, with the full text of any potentially eligible publication retrieved for subsequent review by two independent reviewers. Disagreements during full-text review were resolved by consensus or, when necessary, by a third reviewer. Based on our prespecified inclusion criteria, publications were included if they (1) reported data from RCTs comparing a CETP inhibitor (other than torcetrapib) to placebo; (2) included participants older than 18 years of age; (3) were not reviews, editorials, or letters to the editor; (4) included at least 100 participants; (5) had a follow-up duration of at least 6 months; and (6) reported at least one of our primary or secondary outcomes such as major adverse cardiovascular events (MACE) or its components, or lipid levels (see outcomes below). If multiple publications from the same trial were available, the publication with the largest and most complete reporting was included in our review. Conference abstracts were excluded if we were able to find a corresponding published manuscript to include in our study.

\section{Data Extraction}

Two independent reviewers extracted data from RCTs that met the inclusion criteria into a standardized, pilot-tested database. Discrepancies were resolved by consensus or by a third reviewer. Extracted study characteristics were year of publication, location of enrollment sites, overall number of participants, number of participants in each arm, study duration, and drug regimen. Baseline patient characteristics included age, sex, body mass index, statin use, and the prevalence of cardiovascular risk factors such as diabetes and hypertension. Finally, baseline levels of HDL-c and LDL-c were also recorded.

Our primary outcome of interest was MACE, including nonfatal myocardial infarction (MI), stroke, hospitalization for unstable angina, revascularization events, and cardiovascular death. Our secondary outcomes were the individual components of MACE, all-cause mortality, and lipid levels (LDL-c and HDL-c) at the reported longest follow-up and/or their percent changes from baseline to the longest follow-up.

\section{Quality Assessment}

We assessed the quality of included studies using the Cochrane Collaboration's tool for assessing risk of bias [8]. The tool incorporates the following criteria: sequence generation, allocation concealment, blinding of participants, personnel and outcome assessors, incomplete outcome data, selective outcome reporting and other potential sources of bias. Each domain was given a score of "high," "low," or "unclear" by two independent reviewers, and disagreements were resolved by consensus or by a third reviewer when necessary.

\section{Statistical Analysis}

We used DerSimonian and Laird random-effects models with inverse variance weighting to pool count data across included RCTs and estimate relative risks (RR) and the corresponding 95\% confidence intervals (CI). Our primary analysis pooled data across all CETP inhibitors, and secondary analyses were stratified by CETP inhibitor molecule. We used the treatment arm continuity correction in RCTs with zero events in both arms. $I^{2}$ values were calculated to estimate the amount of between-study heterogeneity that was present. All analyses were conducted using $\mathrm{R}$ version 3.4.1. 
Fig. 1. PRISMA flowchart describing the systematic literature search and the inclusion and exclusion of trials comparing cholesteryl ester transfer protein (CETP) inhibitors to placebo.

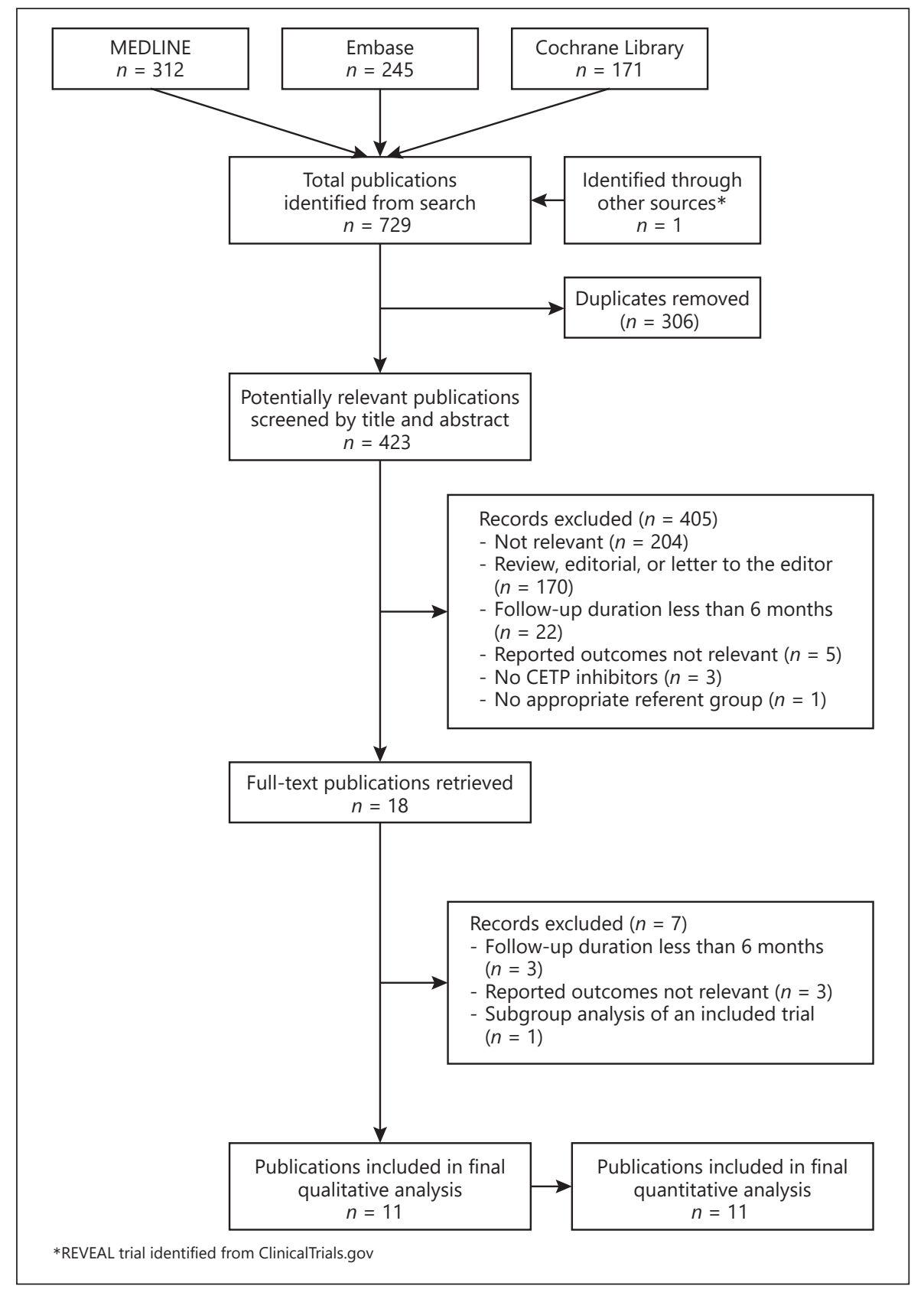

\section{Results}

\section{Search Results}

Our electronic search identified 729 potentially relevant publications (Fig. 1). One additional trial was identified via ClinicalTrials.gov [3]. We removed 306 duplicate records and screened the titles and abstracts of the remaining 423 records. A total of 18 underwent full-text review, of which 11 RCTs met our inclusion criteria and were included in our study [3, 4, 9-19].

\section{Study and Patient Characteristics}

Overall, the 11 included RCTs randomized a total of 62,431 patients (Table 1 ). The sample sizes ranged from 130 to 30,449 participants, and the follow-up durations ranged between 24 weeks and 4.1 years. Dalcetrapib was studied in 4 RCTs $(n=16,612)$, anacetrapib in $6(n=$ $33,682)$, and evacetrapib in $1(n=12,092)$. Each CETP inhibitor had a large RCT with at least 12,000 participants. No studies on TA-8995 met our inclusion criteria; this finding was not unexpected since TA-8995 is in ear- 
Table 1. Characteristics of randomized controlled trials comparing the use of a CETPi to placebo

\begin{tabular}{|c|c|c|c|c|c|c|c|}
\hline \multirow[t]{2}{*}{ Study, year } & \multirow[t]{2}{*}{ Enrollment sites } & \multirow[t]{2}{*}{ Inclusion criteria } & \multirow[t]{2}{*}{ Total, n } & \multicolumn{2}{|l|}{ Arm, n } & \multirow[t]{2}{*}{$\mathrm{F} / \mathrm{U}$ duration } & \multirow{2}{*}{$\begin{array}{l}\text { Daily } \\
\text { dose, } \\
\text { mg }\end{array}$} \\
\hline & & & & CETPi & placebo & & \\
\hline $\begin{array}{l}\text { Dalcetrapib } \\
\text { dal-OUTCOMES } \\
{[15], 2012}\end{array}$ & $\begin{array}{l}27 \text { countries in } \\
\text { North America, } \\
\text { Europe, Asia, and } \\
\text { Australia }\end{array}$ & $\begin{array}{l}\text { Patients } 45 \text { years of age or older who had } \\
\text { recently been hospitalized for an ACS }\end{array}$ & 15,871 & 7,938 & 7,933 & $\begin{array}{l}36 \text { months } \\
\text { (median } 31 \\
\text { months) }\end{array}$ & 600 \\
\hline $\begin{array}{l}\text { dal-VESSEL } \\
{[14], 2012}\end{array}$ & $\begin{array}{l}7 \text { countries in } \\
\text { Europe }\end{array}$ & $\begin{array}{l}\text { 18- to } 75 \text {-year-old patients with CAD or at } \\
\text { high risk for CAD with } \mathrm{HDL}-\mathrm{c}<50 \mathrm{mg} / \mathrm{dL}\end{array}$ & 476 & 238 & 238 & 36 weeks & 600 \\
\hline $\begin{array}{l}\text { dal-PLAQUE } \\
{[12], 2011}\end{array}$ & USA, Canada & $\begin{array}{l}18 \text { - to } 75 \text {-year-old patients with CAD or at } \\
\text { high risk for CAD }\end{array}$ & 130 & 64 & 66 & 24 months & 600 \\
\hline $\begin{array}{l}\text { Stein et al. } \\
{[16], 2010}\end{array}$ & USA, Germany & $\begin{array}{l}18 \text { - to } 75 \text {-year-old patients with CAD or at } \\
\text { high risk for CAD }\end{array}$ & 135 & 89 & 46 & $\begin{array}{l}24 \text { weeks core, } \\
24 \text { weeks extension }\end{array}$ & 900 \\
\hline \multicolumn{8}{|l|}{ Anacetrapib } \\
\hline $\begin{array}{l}\text { REVEAL } \\
{[3], 2017}\end{array}$ & $\begin{array}{l}\text { Europe, North } \\
\text { America, China }\end{array}$ & $\begin{array}{l}\text { Patients older than } 50 \text { years with high } \\
\text { cardiovascular risk }\end{array}$ & 30,449 & 15,225 & 15,224 & 4.1 years & 100 \\
\hline $\begin{array}{l}\text { DEFINE } \\
{[11], 2010}\end{array}$ & $\begin{array}{l}20 \text { countries in } \\
\text { North America, } \\
\text { Europe, Asia, and } \\
\text { Australia }\end{array}$ & $\begin{array}{l}18-80 \text { years old with } \mathrm{CHD} \text { or at high risk } \\
\text { for } \mathrm{CHD}\end{array}$ & 1,623 & 811 & 812 & $\begin{array}{l}24 \text { weeks lipids, } \\
52 \text { weeks extension }\end{array}$ & 100 \\
\hline $\begin{array}{l}\text { Ballantyne et al. } \\
{[10], 2017}\end{array}$ & $\begin{array}{l}\text { Brazil, Russia, } \\
\text { China, Korea, } \\
\text { Taiwan, Turkey, } \\
\text { Mexico }\end{array}$ & $\begin{array}{l}\text { 18-80 years old with hypercholesterolemia } \\
\text { who were not at their LDL-c goal per } \\
\text { NCEP ATP III coronary heart disease risk }\end{array}$ & 583 & 290 & 293 & 24 weeks & 100 \\
\hline $\begin{array}{l}\text { Ballantyne et al. } \\
{[9], 2017}\end{array}$ & NR & $\begin{array}{l}\text { 18-80 years old with hypercholesterolemia } \\
\text { who were not at their LDL-c goal per } \\
\text { NCEP ATP III coronary heart disease risk }\end{array}$ & $459 \ddagger$ & 153 & 154 & 36 weeks & 100 \\
\hline $\begin{array}{l}\text { Teramoto et al. } \\
{[17], 2017}\end{array}$ & Japan & $\begin{array}{l}\text { 18-80 years old with dyslipidemia who } \\
\text { were not at their LDL-c goal }\end{array}$ & 307 & 204 & 103 & 52 weeks & 100 \\
\hline $\begin{array}{l}\text { REALIZE } \\
{[13], 2015}\end{array}$ & $\begin{array}{l}9 \text { countries in } \\
\text { Europe }\end{array}$ & $\begin{array}{l}18-80 \text { years old with genotype-confirmed } \\
\text { or clinical diagnosis } \\
\text { of heterozygous familial } \\
\text { hypercholesterolemia }\end{array}$ & 306 & 204 & 102 & 52 weeks & 100 \\
\hline \multicolumn{8}{|l|}{ Evacetrapib } \\
\hline $\begin{array}{l}\text { ACCELERATE } \\
{[4], 2017}\end{array}$ & $\begin{array}{l}36 \text { countries in } \\
\text { North America, } \\
\text { South America, } \\
\text { Europe, Asia, and } \\
\text { Australia }\end{array}$ & $\begin{array}{l}18 \text { years and older who had high-risk } \\
\text { vascular disease, treated with statin for } \\
30 \text { days before screening }\end{array}$ & 12,092 & 6,038 & 6,054 & $\begin{array}{l}26 \text { months } \\
\text { (median) }\end{array}$ & 130 \\
\hline
\end{tabular}

lier stages of development compared to the other drugs [18].

Included participants (Table 2) were predominantly male (between 55 and $90 \%$ ) with a mean age ranging from 55.0 to 64.8 years. Most trials recruited patients with al- ready established cardiovascular disease (e.g., history of acute coronary syndrome) or at high risk for cardiovascular disease (e.g., had risk factors such as diabetes or hypercholesterolemia). One trial included patients with genetically confirmed familial hypercholesterolemia [13]. 


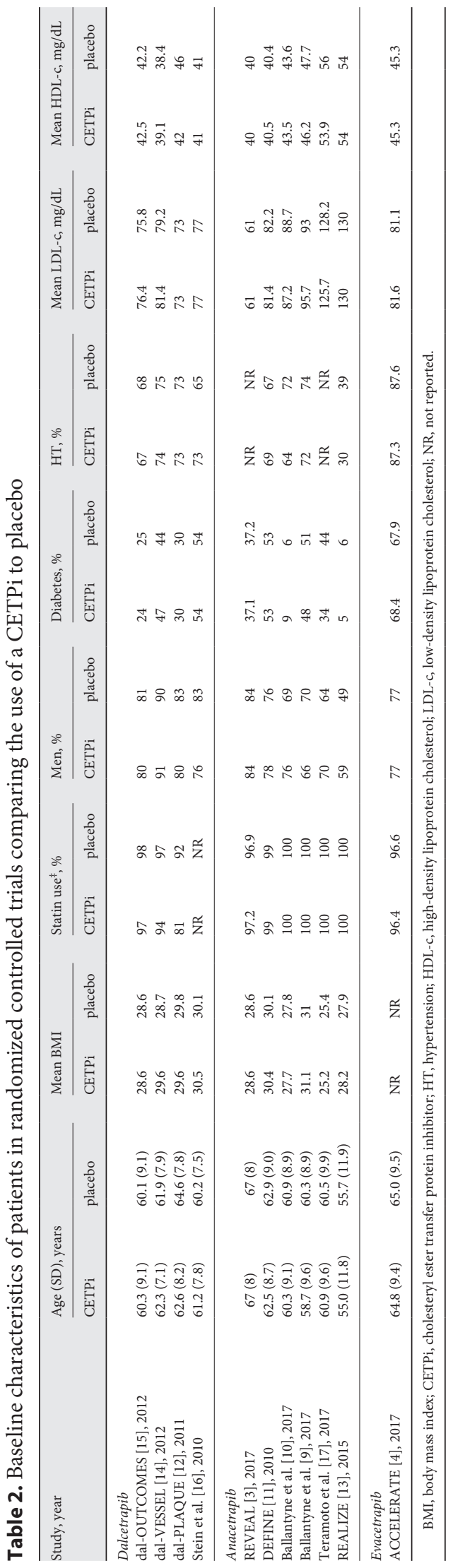

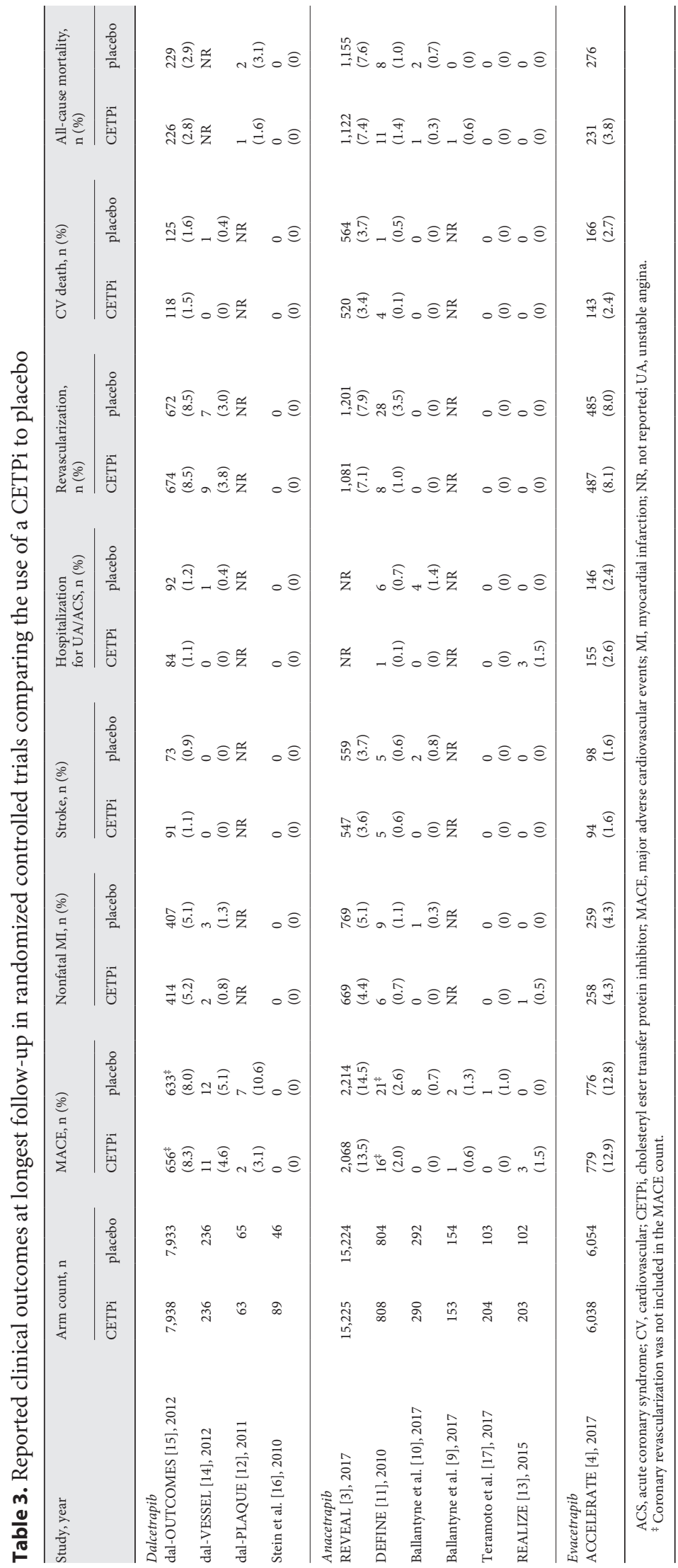




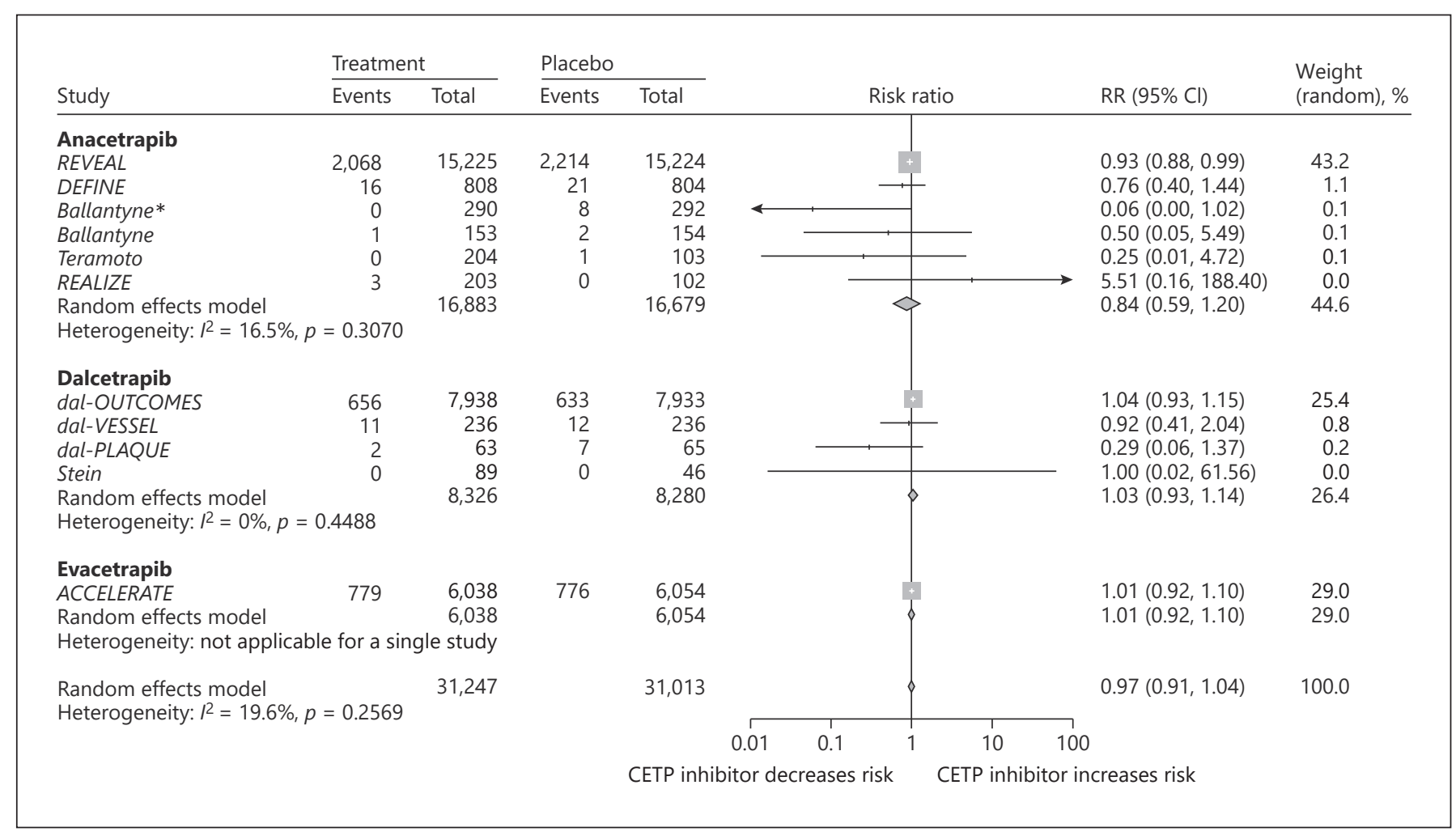

Fig. 2. Forest plot comparing the relative risk of MACE at longest follow-up in patients randomized to a cholesteryl ester transfer protein (CETP) inhibitor compared with patients randomized to placebo. MACE, major adverse cardiovascular event; CI, confidence interval; RR, relative risk. The asterisk indicates Ballantyne et al. [10] in contrast to Ballantyne et al. [9], both references from 2017.

On average, more than $90 \%$ of enrolled patients were already taking statins or were given statins prior to randomization. Mean LDL-c levels at baseline were below $100 \mathrm{mg} / \mathrm{dL}$ for all trials except for 2: one that included patients with heterozygous familial hypercholesterolemia and another that included patients with dyslipidemia refractory to statins $[13,17]$. In all trials, patients' mean serum HDL-c levels were lower than $60 \mathrm{mg} / \mathrm{dL}$.

\section{Quality Assessment}

All included trials had a low risk of bias according to the Cochrane Collaboration's Tool for Assessing Risk of Bias (Appendix 4). They were double-blinded and included placebo as a comparator. Sequence generation and allocation concealment criteria were not clearly described in 4 out of 11 studies $[9,10,16,17]$.

\section{MACE and Its Components}

Most included trials reported MACE (Table 3) as a composite incidence of cardiovascular death, nonfatal MI, hospitalization due to unstable angina or acute coronary syndrome, stroke, and coronary revascularization. In the REVEAL trial, hospitalization for unstable angina was not included as part of their composite end point. Two studies did not include revascularization as a component of MACE $[11,15]$. Certain trials, such as dal-PLAQUE, did not report many of the secondary outcomes of interest [12].

Overall, pooled data suggest that CETP inhibitors do not decrease MACE compared to placebo (RR: 0.97; 95\% CI: 0.91-1.04) (Fig. 2). Similarly, pooled data across all CETP inhibitors found no difference in risks of stroke (RR: 1.00; 95\% CI: 0.90-1.11) (Appendix 5), hospitalization due to acute coronary syndrome (RR: 0.99 ; $95 \%$ CI: $0.83-1.18$ ) (Appendix 6), revascularization (RR: 0.95; 95\% CI: 0.851.05) (Appendix 7) or all-cause mortality (RR: 0.95; 95\% CI: 0.89-1.02) (Appendix 8). However, our pooled data suggest that CETP inhibitors may modestly decrease the risks of nonfatal MI (RR: 0.93; 95\% CI: 0.87-1.00) (Fig. 3) and cardiovascular death (RR: 0.92; 95\% CI: 0.83-1.01) (Appendix 9), though these trends did not reach statistical significance. Analyses stratified by CETP inhibitor found no difference in MACE or its components, with one exception: 


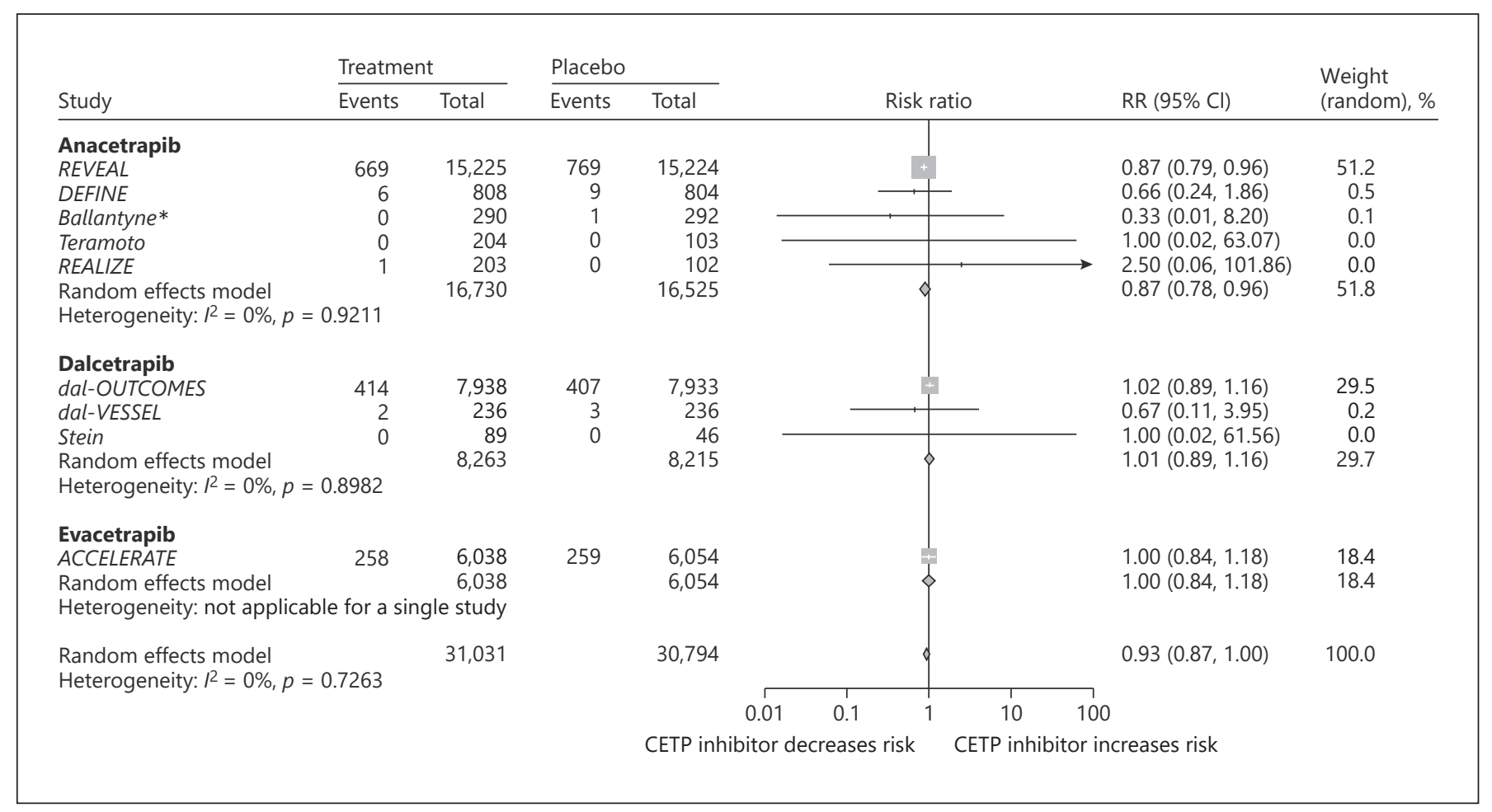

Fig. 3. Forest plot comparing the relative risk of nonfatal myocardial infarction at longest follow-up in patients randomized to a cholesteryl ester transfer protein (CETP) inhibitor compared with patients randomized to placebo. CI, confidence interval; RR, relative risk. The asterisk indicates Ballantyne et al. [10], 2017.

patients randomized to anacetrapib had a reduced risk of nonfatal MI compared to those randomized to placebo (RR: 0.87; 95\% CI: 0.78-0.96) (Fig. 3). This finding was mainly driven by the results from the REVEAL trial [3].

\section{Changes in Plasma Lipid Levels}

CETP inhibitors increased HDL-c with varying efficacy (Table 4). In the REVEAL trial, anacetrapib increased mean HDL-c levels from 38 to $85 \mathrm{mg} / \mathrm{dL}$, a relative increase of $104 \%$. Similarly, in the ACCELERATE trial, treatment with evacetrapib increased mean HDL-c levels from 54.7 to $104.1 \mathrm{mg} / \mathrm{dL}$ (133.2\% increase). Dalcetrapib, in contrast, had a milder impact on HDL-c. In the dal-PLAQUE study, dalcetrapib increased HDL-c by $30.9 \%$ from baseline. The observed changes were consistent with those of smaller trials included in our review.

In addition to increasing HDL-c levels, anacetrapib and evacetrapib decreased LDL-c levels in all included trials. In the ACCELERATE trial, treatment with evacetrapib decreased LDL-clevels by $31.1 \%$. Interestingly, in both anacetrapib trials with statin-treated patients with mean baseline LDL-c levels of more than $100 \mathrm{mg} / \mathrm{dL}$, treatment with anacetrapib significantly lowered serum LDL-c lev- els: in the REALIZE trial, patients with familial hypercholesterolemia had lower mean LDL-c levels $(79.0 \mathrm{mg} / \mathrm{dL}$ in the treated group compared to $126.7 \mathrm{mg} / \mathrm{dL}$ in the placebo group) [13]. Likewise, in the trial by Teramoto et al. [19], a similar change was observed, with a mean $31.3 \%$ reduction in LDL-c. In contrast to anacetrapib and evacetrapib, dalcetrapib had a minimal impact on mean LDL-c.

\section{Discussion}

Our systematic review with meta-analysis was designed to assess the impact of CETP inhibitors (anacetrapib, dalcetrapib, and evacetrapib) on clinical outcomes and serum lipid profiles. Although we found no benefit for MACE or all-cause mortality, there was a trend towards reduced risks of nonfatal MI and cardiovascular death. However, the clinical significance of these potential benefits is likely modest. When analyses were stratified by drug, there was no difference in any outcome except for anacetrapib, which reduced the incidence of nonfatal MI. All CETP inhibitors increased HDL-c, to varying degrees, with anacetrapib and evacetrapib appearing to increase HDL-c substantively 
Table 4. Reported lipid outcomes at longest follow-up in randomized controlled trials comparing the use of a CETPi to placebo

\begin{tabular}{|c|c|c|c|c|c|c|c|c|}
\hline \multirow[t]{2}{*}{ Study, year } & \multicolumn{2}{|c|}{$\begin{array}{l}\text { Mean LDL-c } \\
(\mathrm{SD}), \mathrm{mg} / \mathrm{dL}\end{array}$} & \multicolumn{2}{|c|}{$\begin{array}{l}\text { LDL-c percent change } \\
\text { from baseline (SD or IQR) }\end{array}$} & \multicolumn{2}{|c|}{$\begin{array}{l}\text { Mean HDL-c } \\
(\mathrm{SD}), \mathrm{mg} / \mathrm{dL}\end{array}$} & \multicolumn{2}{|c|}{$\begin{array}{l}\text { HDL-c percent change } \\
\text { from baseline (SD or IQR) }\end{array}$} \\
\hline & CETPi & placebo & CETPi & placebo & CETPi & placebo & CETPi & placebo \\
\hline \multicolumn{9}{|l|}{ Dalcetrapib } \\
\hline dal-OUTCOMES [15], 2012 & NR & NR & NR & NR & NR & NR & NR & NR \\
\hline dal-VESSEL [14], 2012 & NR & NR & $\begin{array}{l}4.4 \\
(2.2)\end{array}$ & $\begin{array}{l}8.7 \\
(21.8)\end{array}$ & NR & NR & $\begin{array}{l}30.7 \\
(1.4)\end{array}$ & $\begin{array}{l}-0.1 \\
(1.4)\end{array}$ \\
\hline Stein et al. [16], 2010 & NR & NR & $\begin{array}{l}4.8 \\
(\mathrm{NR})\end{array}$ & $\begin{array}{l}3.0 \\
(\mathrm{NR})\end{array}$ & NR & NR & $\begin{array}{l}33.8 \\
(\mathrm{NR})\end{array}$ & $\begin{array}{l}3.7 \\
(\mathrm{NR})\end{array}$ \\
\hline \multicolumn{9}{|l|}{ Anacetrapib } \\
\hline REVEAL [3], 2017 & $\begin{array}{l}38 \\
(\mathrm{NR})\end{array}$ & $\begin{array}{l}64 \\
(\mathrm{NR})\end{array}$ & NR & NR & $\begin{array}{l}85 \\
(\mathrm{NR})\end{array}$ & $\begin{array}{l}42 \\
(\mathrm{NR})\end{array}$ & NR & NR \\
\hline Ballantyne et al. [9], 2017 & $\begin{array}{l}68.6 \\
(36.8)\end{array}$ & $\begin{array}{l}96.6 \\
(33.2)\end{array}$ & $\begin{array}{l}-28 \\
(-33.7,-22.3)\end{array}$ & $\begin{array}{l}0.9 \\
(-4.9,6.7)\end{array}$ & $\begin{array}{l}91.7 \\
(32.2)\end{array}$ & $\begin{array}{l}48.5 \\
(14.0)\end{array}$ & $\begin{array}{l}98.6 \\
(91.7,105.4)\end{array}$ & $\begin{array}{l}3.9 \\
(-2.9,10.7)\end{array}$ \\
\hline Teramoto et al. [17], 2017 & $\begin{array}{l}79.0 \\
(30.6)\end{array}$ & $\begin{array}{l}126.7 \\
(32.2)\end{array}$ & $\begin{array}{l}-31.3 \\
(-41.7,-36.6)\end{array}$ & $\begin{array}{l}-1.1 \\
(-4.7,2.5)\end{array}$ & $\begin{array}{l}135.8 \\
(25.9)\end{array}$ & $\begin{array}{l}59.8 \\
(13.8)\end{array}$ & $\begin{array}{l}157.6 \\
(152.9,162.3)\end{array}$ & $\begin{array}{l}8.7 \\
(2.2,15.2)\end{array}$ \\
\hline REALIZE [13], 2015 & $\begin{array}{l}81.2 \\
(30.9)\end{array}$ & $\begin{array}{l}135.3 \\
(61.9)\end{array}$ & $\begin{array}{l}-36.0 \\
(-39.5,-32.5)\end{array}$ & $\begin{array}{l}3.7 \\
(-1.2,8.6)\end{array}$ & $\begin{array}{l}108.3 \\
(27.1)\end{array}$ & $\begin{array}{l}54.1 \\
(15.5)\end{array}$ & $\begin{array}{l}105.8 \\
(101.1,110.6)\end{array}$ & $\begin{array}{l}3.7 \\
(-2.8,10.3)\end{array}$ \\
\hline \multicolumn{9}{|l|}{ Evacetrapib } \\
\hline ACCELERATE [4], 2017 & $\begin{array}{l}54.7 \\
(26.4)\end{array}$ & $\begin{array}{l}83.7 \\
(30.8)\end{array}$ & $\begin{array}{l}-31.1 \\
(27.6)\end{array}$ & $\begin{array}{l}6.0 \\
(29.0)\end{array}$ & $\begin{array}{l}104.1 \\
(31.4)\end{array}$ & $\begin{array}{l}45.6 \\
(12.3)\end{array}$ & $\begin{array}{l}133.2 \\
(57.2)\end{array}$ & $\begin{array}{l}1.6 \\
(17.5)\end{array}$ \\
\hline
\end{tabular}

CETPi, cholesteryl ester transfer protein inhibitor; HDL-c, high-density lipoprotein cholesterol; IQR, interquartile range; LDL-c, low-density lipoprotein cholesterol; SD, standard deviation.

more than dalcetrapib. Dalcetrapib also had a minimal effect on LDL-c, whereas anacetrapib and evacetrapib significantly decreased LDL-c compared to placebo.

The effect of HDL-raising medications on cardiovascular outcomes and lipid levels has previously been studied [2, 20, 21]; however, our meta-analysis includes 2 more recent large clinical trials (REVEAL and ACCELERATE), which provided 42,541 additional patients. Previous meta-analyses also included torcetrapib, which was no longer under investigation at the time of our search due to unexpected increases in mortality (RR: 1.25 ; 95\% CI: 1.09-1.44) compared to placebo [6]. This increase was attributed to offtarget effects of torcetrapib on aldosteronelevels that caused an increase in blood pressure (mean increase in systolic blood pressure of $5.4 \mathrm{~mm} \mathrm{Hg}$ ) [22]. Subsequently developed CETP inhibitors have limited adverse effects on blood pressure. A small increase in systolic blood pressure was observed with dalcetrapib (mean increase of $0.6 \mathrm{~mm} \mathrm{Hg}$ ) [15] and anacetrapib (mean increase of $0.7 \mathrm{~mm} \mathrm{Hg}$ ) [3], and no effect on blood pressure was seen with evacetrapib [23].

Our findings are consistent with previous studies that suggest uncertain clinical benefit from raising HDL-c, despite a biological rationale for improved cardiovascular outcomes with increased HDL-c. A meta-analysis of HDL-raising drugs, including niacin, fibrates, and CETP inhibitors, found no association with cardiovascular mortality, stroke, or all-cause mortality [24]. HDL-c modifiers did reduce the risk of MI; however, this benefit was attenuated when the analysis was restricted to trials in which participants also used statins [24]. This finding is consistent with previous research which indicates that while drugs such as niacin and fibrates mildly increase HDL-c levels by $20-30 \%$ [25], when tested in trials with patients taking statins, these drugs fail to improve clinical outcomes [2]. CETP inhibitors are the most recent addition to the family of HDL-c-raising agents. 
HDL-c-raising agents are lipophilic molecules that inhibit the cholesteryl ester transfer protein. This enzyme facilitates the exchange of cholesteryl esters and triglycerides between HDL-c particles and apolipoprotein B (ApoB)-associated lipoproteins such as LDL and very-lowdensity lipoprotein. As HDL-c particles are progressively depleted of their cholesteryl esters and are enriched with triglycerides, they are cleared from the plasma more rapidly. Based on epidemiological studies, higher serum HDL-c levels are associated with more favorable clinical outcomes [26]. One proposed mechanism for such clinical benefit is the "reverse cholesterol pathway," which is primarily supported by animal studies [27]. This hypothesis suggests that HDL-c reduces plaque burden by transporting cholesteryl esters from atherosclerotic lesions to the liver and other steroidogenic tissues [28].

Most CETP inhibitors simultaneously increase HDL-c and decrease LDL-c levels. However, dalcetrapib increases HDL-c without having a significant impact on LDL-c. This difference has been attributed to its smaller chemical structure lacking a trifluoride moiety [29]. In the dalOUTCOMES trial $(n=15,871)$, dalcetrapib failed to improve clinical outcomes in patients with a recent episode of acute coronary syndrome [15]. Its use was associated with a mild $(0.6 \mathrm{~mm} \mathrm{Hg})$ increase in systolic blood pressure as well as an increase in high-sensitivity C-reactive protein levels by $18 \%$. Increases in high-sensitivity C-reactive protein have also been observed with torcetrapib (3\% increase) and evacetrapib (9\% increase) [30]. DNA analysis on samples from the dal-OUTCOMES and dalPLAQUE trials found a differing therapeutic response to dalcetrapib depending on the patients' genotype. An AA allele was associated with improved cholesterol efflux and no significant increase in C-reactive protein levels. A trial is currently under way to evaluate the impact of this drug on cardiovascular outcomes in participants with the AA phenotype, with results expected in 2020 (NCT02525939).

Anacetrapib and evacetrapib have similar impacts on serum lipid profiles. They are potent HDL-c-raising agents that simultaneously reduce LDL-c levels in patients already treated with statins. Despite the similarities, the REVEAL trial (anacetrapib) found a reduction in coronary events (coronary death, MI, and revascularization) at 3 years, while ACCELERATE (evacetrapib) was terminated for futility after 26 months [4]. In REVEAL, it was not until the third year of treatment that improvements in clinical outcomes were observed. Nonetheless, there was a trend towards better outcomes by the end of the second year of REVEAL. Anacetrapib has an extended half-life compared to the other CETP inhibitors, with re- sidual effects on lipid levels lasting more than 12 weeks after treatment discontinuation, and detectable levels of the drug 4 years after discontinuation [31]. It has now been shown that anacetrapib accumulates in adipose tissues [32]. Unlike anacetrapib, there was no sign of improvement in outcomes in ACCELERATE after 2 years.

Overall, it would be reasonable to expect the reductions in LDL-c with anacetrapib and evacetrapib to be associated with improved cardiovascular outcomes, regardless of improvements in HDL-c. However, a Mendelian randomization study offers a plausible explanation for why this is not the case. This study suggests that the combined reduction of LDL-c using statins and CETP inhibition causes an attenuated reduction in Apo-B relative to LDL-c levels [33]. Therefore, when both 3-hydroxy3-methylglutaryl coenzyme A and CETP are inhibited using statins and CETP inhibitors, one might not observe the improved clinical outcomes associated with the reduction of LDL-c levels. A clinical trial in which a CETP inhibitor is used without concomitant statin use could test this hypothesis. Further research is needed to explain why anacetrapib is associated with some improvements in cardiovascular outcomes, while evacetrapib is not.

Overall, it appears unlikely that CETP inhibitors will provide sufficient cardiovascular benefits to justify routine use. Torcetrapib was withdrawn due to increased mortality [6], and large dalcetrapib and evacetrapib trials were stopped early for futility $[4,15]$. While anacetrapib has a similar efficacy and safety profile as some routinely used nonstatins (e.g., ezetimibe), regulatory approval is not being sought [30]. Our study had several potential limitations. First, our primary objective was to assess the association between CETP inhibitors and cardiovascular outcomes. Consequently, we restricted inclusion to studies which included at least 100 participants and had follow-up duration of at least 6 months. This restriction limited our review of lipid changes, which have been assessed in small, short-term trials. Nonetheless, our findings remained consistent with those of previous studies. Second, there was some variation in study design (e.g., population, follow-up duration). For this reason, we used randomeffects models to account for both within- and betweenstudy variability. Third, we were not able to include TA8995 in our analysis, as it is still in earlier stages of development and no studies were available that met our inclusion criteria. Lastly, given the differential effects of anacetrapib, dalcetrapib, and evacetrapib on HDL-c and LDL-c, and varying elimination half-lives, it is possible that the cardiovascular benefits may vary by CETP inhibitor. However, the limited absolute number of adverse 
events at this time makes it reasonable to examine this group of drugs as a class, as a preliminary assessment of the impact of CETP inhibitors on cardiovascular events.

\section{Conclusion}

Overall, despite being efficient at increasing HDL-c, CETP inhibitors were not associated with improvements in cardiovascular outcomes overall or all-cause mortality. While pooled data suggest that there is a trend towards small reductions in nonfatal MI and cardiovascular death with the use of CETP inhibitors, the clinical significance of such reductions is likely modest, with anacetrapib driving the potential reduction in nonfatal MI. Further research is needed to clarify the relationship between raising HDL-c and cardiovascular events.

\section{Acknowledgments}

We would like to thank Ms. Maria Alcaraz and Mr. Zachary Dionisopoulos for their assistance with full-text article screening and data extraction.

\section{Disclosure Statement}

The authors have no conflicts of interest to declare.

\section{Funding Sources}

Mr. Taheri is supported by a Mach-Gaensslen Foundation of Canada Student Grant funded through the McGill University Research Bursary Program. Dr. Filion is supported by a career award from the Quebec Foundation for Health Research and a William Dawson Scholar award from McGill University. There are no competing interests to declare.

\section{Author Contributions}

Dr. Eisenberg and Dr. Filion conceived, designed, and oversaw the conduct of the study. Mr. Taheri executed the literature search and wrote the initial draft of this manuscript. Ms. Reynier analyzed the data. All authors critically revised the manuscript for important intellectual content. All authors are responsible for the content of the manuscript and have read and approved the final paper.

\section{Appendix 1}

Description of MEDLINE search through Ovid for trials including evacetrapib, dalcetrapib, anacetrapib, or obicetrapib.

\begin{tabular}{llr}
\hline Search No. & Search term & Number of results \\
\hline 1 & (obicetrapib or ta-8995).mp & 11 \\
2 & (evacetrapib or ly2484595).mp & 88 \\
3 & (dalcetrapib or jtt-705).mp & 225 \\
4 & (anacetrapib or mk-0859).mp & 200 \\
5 & cholesteryl ester transfer protein inhibitor*.mp & 208 \\
6 & 1 or 2 or 3 or 4 or 5 & 510 \\
7 & ([randomized controlled trial or controlled clinical trial].pt. or randomized.ab. or & $3,613,199$ \\
& randomised.ab. or placebo.ab. or drug therapy.fs. or randomly.ab. or trial.ab. or & \\
8 & groups.ab.) not (exp animals/not humans.sh.) & 312 \\
\hline
\end{tabular}

CETP Inhibitors and Cardiovascular Outcomes
Cardiology 2020;145:236-250 DOI: $10.1159 / 000505365$ 


\section{Appendix 2}

Description of EMBASE search through Ovid for trials including evacetrapib, dalcetrapib, anacetrapib, or obicetrapib.

\begin{tabular}{llc}
\hline Search No. & Search term & Number of results \\
\hline 1 & (obicetrapib or ta-8995).mp & 28 \\
2 & (evacetrapib or ly2484595).mp & 249 \\
3 & (dalcetrapib or jtt-705).mp & 773 \\
4 & (anacetrapib or mk-0859).mp & 626 \\
5 & cholesteryl ester transfer protein inhibitor*.mp & 247 \\
6 & 1 or 2 or 3 or 4 or 5 & 1,188 \\
7 & crossover procedure or double-blind procedure or randomized controlled trial or & $1,889,036$ \\
& single-blind procedure or (random* or factorial* or crossover* or cross over* or placebo** & \\
8 & or [doubl* adj blind*] or [singl* adj blind*] or assign* or allocat* or volunteer*).tw & 245 \\
\hline
\end{tabular}

\section{Appendix 3}

Description of Cochrane search for trials including evacetrapib, dalcetrapib, anacetrapib, or obicetrapib.

\begin{tabular}{llc}
\hline $\begin{array}{l}\text { Search } \\
\text { No. }\end{array}$ & Search term & $\begin{array}{l}\text { Number } \\
\text { of results }\end{array}$ \\
\hline 1 & obicetrapib or ta-8995 & 4 \\
2 & evacetrapib or ly2484595 & 23 \\
3 & dalcetrapib or jtt-705 & 52 \\
4 & anacetrapib or mk-0859 & 47 \\
5 & cholesteryl ester transfer protein & 131 \\
& inhibitor* & 176 \\
\hline
\end{tabular}

\section{Appendix 4}

Quality assessment table.

\begin{tabular}{|c|c|c|c|c|c|c|}
\hline Study & $\begin{array}{l}\text { Sequence } \\
\text { generation }\end{array}$ & $\begin{array}{l}\text { Allocation } \\
\text { concealment }\end{array}$ & $\begin{array}{l}\text { Blinding of participants, } \\
\text { personnel, and outcome } \\
\text { assessors }\end{array}$ & $\begin{array}{l}\text { Incomplete } \\
\text { outcome data }\end{array}$ & $\begin{array}{l}\text { Selective } \\
\text { outcome reporting }\end{array}$ & $\begin{array}{l}\text { Other } \\
\text { sources } \\
\text { of bias }\end{array}$ \\
\hline \multicolumn{7}{|l|}{ Dalcetrapib } \\
\hline dal-OUTCOMES [15], 2012 & low & low & low & low & low & low \\
\hline dal-VESSEL [14], 2012 & low & low & low & low & low & low \\
\hline dal-PLAQUE [12], 2011 & low & & low & low & unclear & low \\
\hline Stein et al. [16], 2010 & unclear & unclear & low & low & low & unclear \\
\hline \multicolumn{7}{|l|}{ Anacetrapib } \\
\hline REVEAL [3], 2017 & low & low & low & low & low & low \\
\hline DEFINE [11], 2010 & low & low & low & low & low & low \\
\hline Ballantyne et al. [10], 2017 & unclear & unclear & low & low & low & low \\
\hline Ballantyne et al. [9], 2017 & unclear & unclear & low & low & low & low \\
\hline Teramoto et al. [17], 2017 & unclear & unclear & low & low & low & low \\
\hline REALIZE [13], 2015 & low & low & low & low & low & low \\
\hline \multicolumn{7}{|l|}{ Evacetrapib } \\
\hline ACCELERATE [4], 2017 & low & low & low & low & low & low \\
\hline
\end{tabular}

For each criterion, the risk of bias was classified as being "high," "low," or "unclear" according to the guidelines of the Cochrane Collaboration's tool for assessing risk of bias. 


\section{Appendix 5}

Forest plot comparing the relative risk of stroke at longest follow-up in patients randomized to a CETP inhibitor compared with patients randomized to placebo. CI, confidence interval; RR, relative risk. The asterisk indicates Ballantyne et al. [10], 2017.

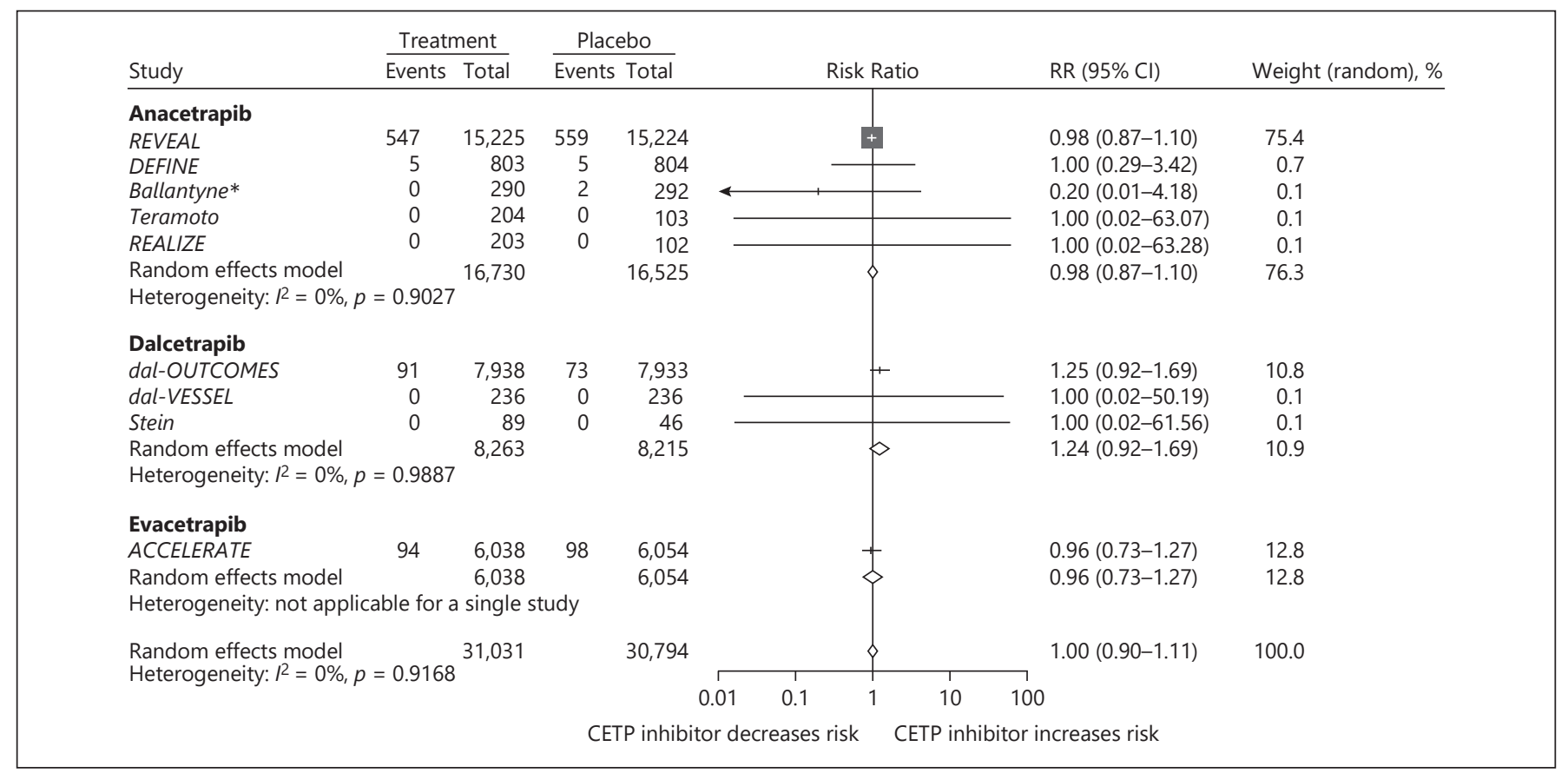

\section{Appendix 6}

Forest plot comparing the relative risk of hospitalization due to acute coronary syndrome at longest follow-up in patients randomized to a CETP inhibitor compared with patients randomized to placebo. CI, confidence interval; RR, relative risk. The asterisk indicates Ballantyne et al. [10], 2017.

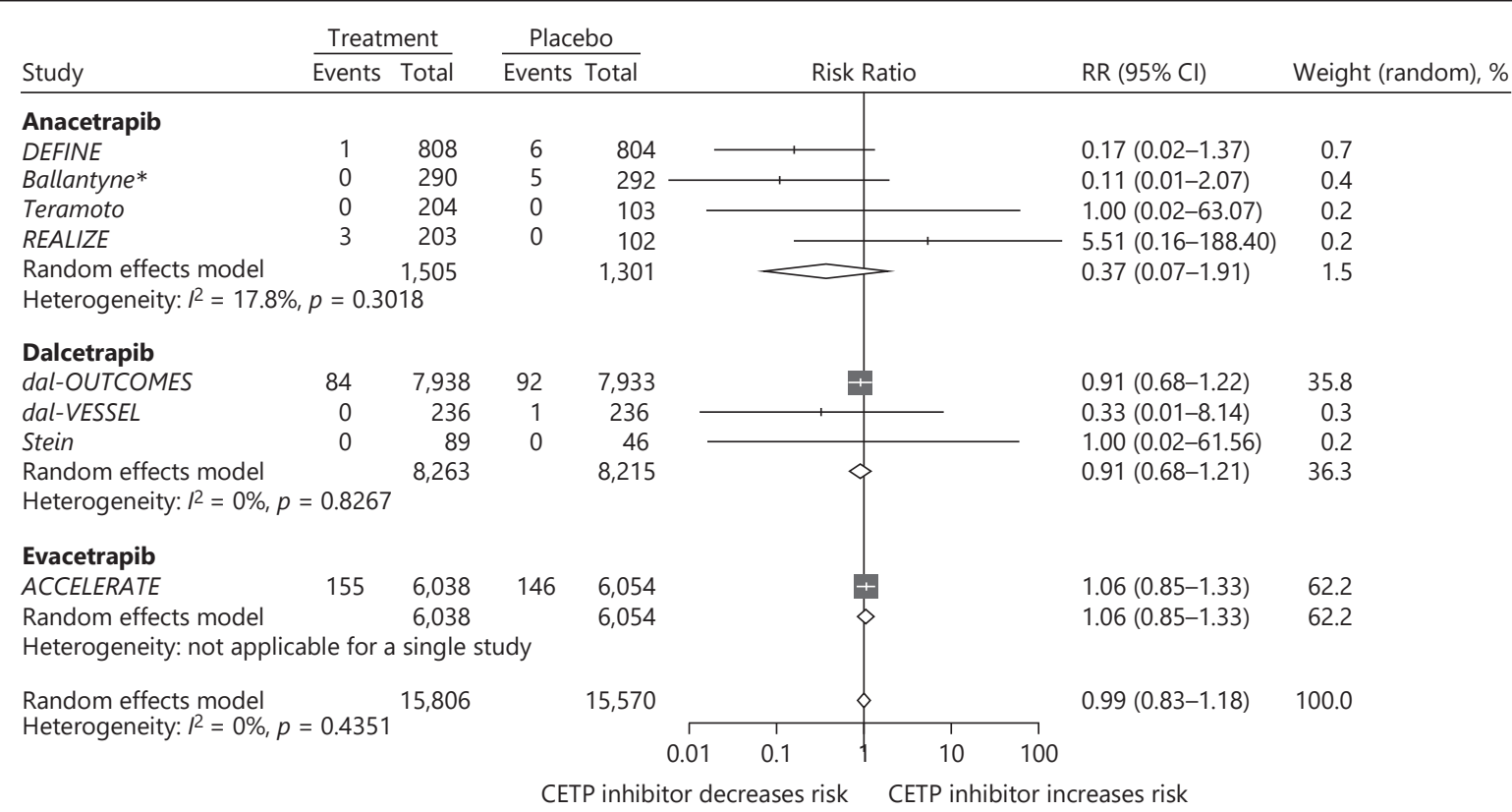

CETP Inhibitors and Cardiovascular Outcomes
Cardiology 2020;145:236-250

DOI: $10.1159 / 000505365$ 


\section{Appendix 7}

Forest plot comparing the relative risk of revascularization at longest follow-up in patients randomized to a CETP inhibitor compared with patients randomized to placebo. CI, confidence interval; RR, relative risk. The asterisk indicates Ballantyne et al. [10], 2017.

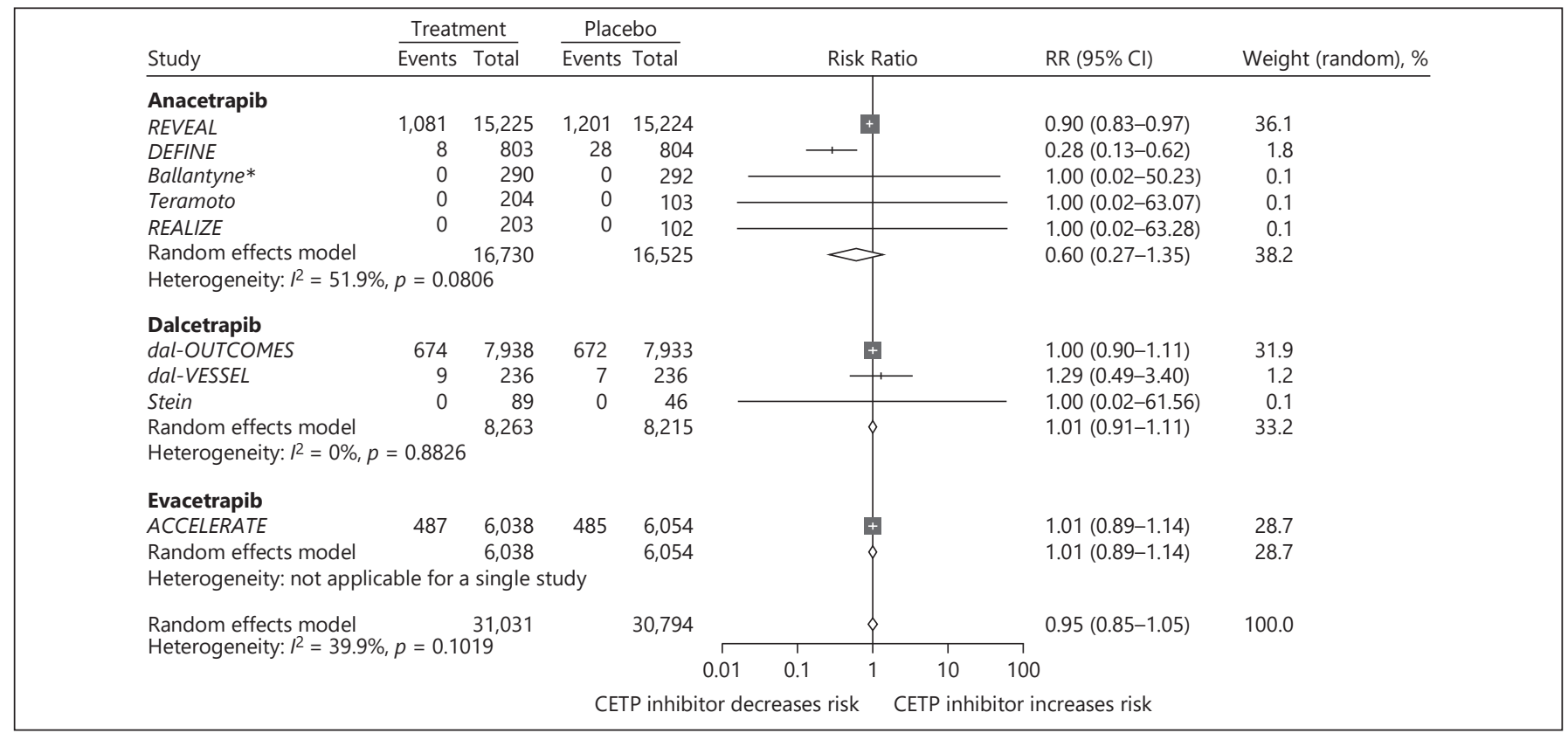

\section{Appendix 8}

Forest plot comparing the relative risk of all-cause mortality at longest follow-up in patients randomized to a CETP inhibitor compared with patients randomized to placebo. CI, confidence interval; RR, relative risk. The asterisk indicates Ballantyne et al. [10] in contrast to Ballantyne et al. [9], both references from 2017.

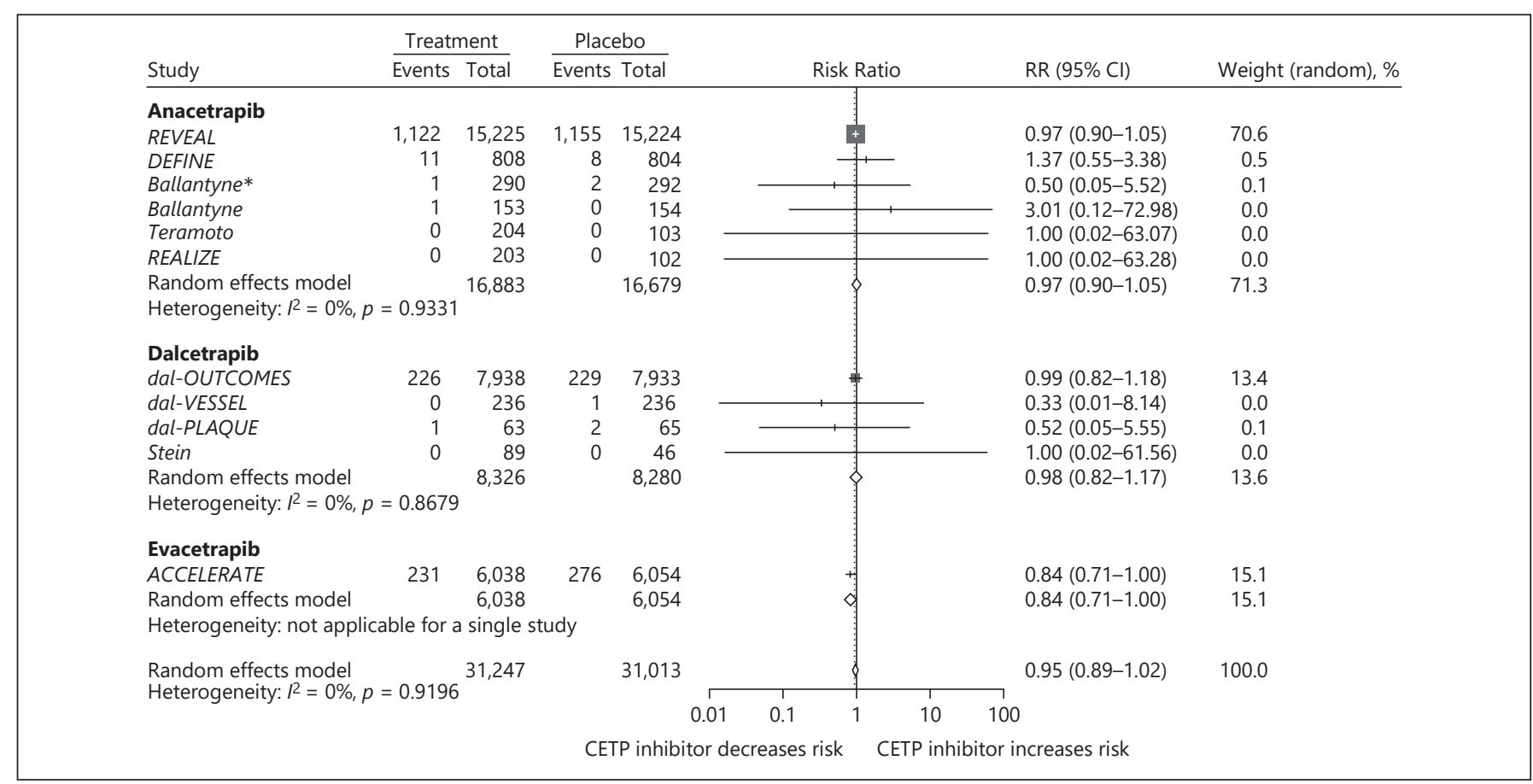




\section{Appendix 9}

Forest plot comparing the relative risk of cardiovascular mortality at longest follow-up in patients randomized to a CETP inhibitor compared with patients randomized to placebo. CI, confidence interval; RR, relative risk. The asterisk indicates Ballantyne et al. [10], 2017.

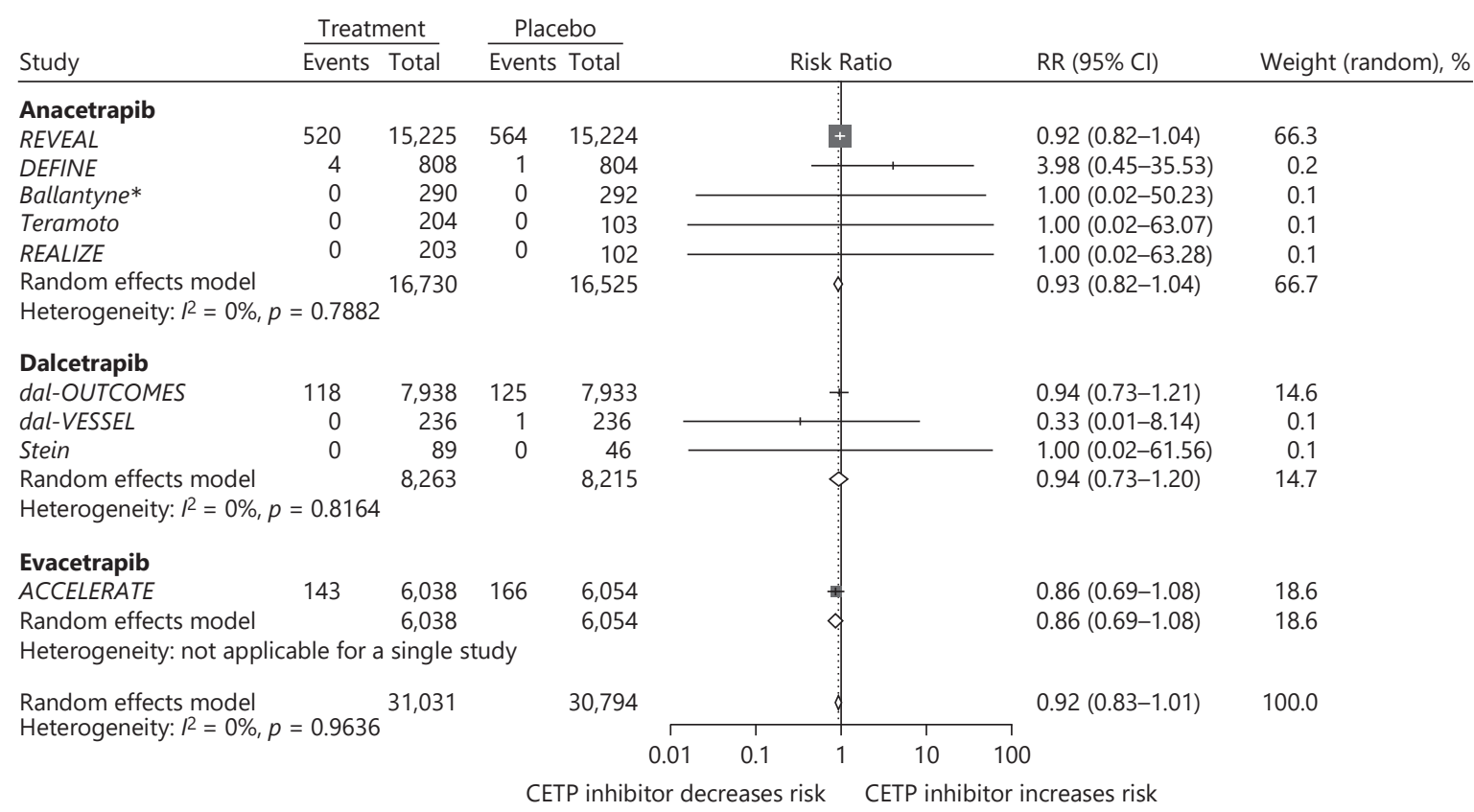

\section{References}

1 Ferri N, Corsini A, Sirtori CR, Ruscica M. Present therapeutic role of cholesteryl ester transfer protein inhibitors. Pharmacol Res. 2018 Feb;128:29-41.

2 Keene D, Price C, Shun-Shin MJ, Francis DP Effect on cardiovascular risk of high density lipoprotein targeted drug treatments niacin, fibrates, and CETP inhibitors: meta-analysis of randomised controlled trials including 117,411 patients. BMJ. 2014 Jul;349:g4379.

3 Bowman L, Hopewell JC, Chen F, Wallendszus K, Stevens W, Collins R, et al.; HPS3/ TIMI55-REVEAL Collaborative Group. Effects of Anacetrapib in Patients with Atherosclerotic Vascular Disease. N Engl J Med. 2017 Sep;377(13):1217-27.

4 Lincoff AM, Nicholls SJ, Riesmeyer JS, Barter PJ, Brewer HB, Fox KA, et al.; ACCELERATE Investigators. Evacetrapib and Cardiovascular Outcomes in High-Risk Vascular Disease. N Engl J Med. 2017 May;376(20):1933-42.

5 Liberati A, Altman DG, Tetzlaff J, Mulrow C, Gøtzsche PC, Ioannidis JP, et al. The PRISMA statement for reporting systematic reviews and meta-analyses of studies that evaluate health care interventions: explanation and elaboration. PLoS Med. 2009 Jul;6(7): e1000100.
6 Barter PJ, Caulfield M, Eriksson M, Grundy SM, Kastelein JJ, Komajda M, et al.; ILLUMINATE Investigators. Effects of torcetrapib in patients at high risk for coronary events. $\mathrm{N}$ Engl J Med. 2007 Nov;357(21):2109-22.

7 Wilczynski NL, McKibbon KA, Haynes RB. Enhancing retrieval of best evidence for health care from bibliographic databases: calibration of the hand search of the literature. Stud Health Technol Inform. 2001;84(Pt 1):390-3.

8 Higgins JP, Altman DG, Gøtzsche PC, Jüni P, Moher D, Oxman AD, et al; Cochrane Bias Methods Group; Cochrane Statistical Methods Group. The Cochrane Collaboration's tool for assessing risk of bias in randomised trials. BMJ. 2011 Oct;343:d5928.

9 Ballantyne CM, Shah S, Kher U, Hunter JA, Gill GG, Cressman MD, et al. Lipid-Modifying Efficacy and Tolerability of Anacetrapib Added to Ongoing Statin Therapy in Patients with Hypercholesterolemia or Low HighDensity Lipoprotein Cholesterol. Am J Cardiol. 2017 Feb;119(3):388-96.

10 Ballantyne CM, Shah S, Sapre A, Ashraf TB, Tobias SC, Sahin T, et al. A multiregional, randomized evaluation of the lipid-modifying efficacy and tolerability of anacetrapib aded to ongoing statin therapy in patients with hypercholester- olemia or low high-density lipoprotein cholesterol. Am J Cardiol. 2017 Aug;120(4):569-76.

11 Cannon CP, Shah S, Dansky HM, Davidson M, Brinton EA, Gotto AM Jr, et al.; Determining the Efficacy and Tolerability Investigators. Safety of anacetrapib in patients with or at high risk for coronary heart disease. $\mathrm{N}$ Engl J Med. 2010 Dec;363(25):2406-15.

12 Fayad ZA, Mani V, Woodward M, Kallend D, Abt M, Burgess T, et al.; dal-PLAQUE Investigators. Safety and efficacy of dalcetrapib on atherosclerotic disease using novel non-invasive multimodality imaging (dal-PLAQUE): a randomised clinical trial. Lancet. 2011 Oct; 378(9802):1547-59.

13 Kastelein JJ, Besseling J, Shah S, Bergeron J, Langslet G, Hovingh GK, et al. Anacetrapib as lipid-modifying therapy in patients with heterozygous familial hypercholesterolaemia (REALIZE): a randomised, double-blind, placebo-controlled, phase 3 study. Lancet. 2015 May;385(9983):2153-61.

14 Lüscher TF, Taddei S, Kaski JC, Jukema JW, Kallend D, Münzel T, et al.; dal-VESSEL Investigators. Vascular effects and safety of dalcetrapib in patients with or at risk of coronary heart disease: the dal-VESSEL randomized clinical trial. Eur Heart J. 2012 Apr;33(7):857-65. 
15 Schwartz GG, Olsson AG, Abt M, Ballantyne CM, Barter PJ, Brumm J, et al.; dal-OUTCOMES Investigators. Effects of dalcetrapib in patients with a recent acute coronary syndrome. N Engl J Med. 2012 Nov;367(22): 2089-99.

16 Stein EA, Roth EM, Rhyne JM, Burgess T, Kallend D, Robinson JG. Safety and tolerability of dalcetrapib (RO4607381/JTT-705): results from a 48-week trial. Eur Heart J. 2010 Feb;31(4):480-8.

17 Teramoto T, Daida H, Ikewaki K, Arai H, Maeda Y, Nakagomi M, et al. Lipid-modifying efficacy and tolerability of anacetrapib added to ongoing statin therapy in Japanese patients with dyslipidemia. Atherosclerosis. 2017 Jun;261:69-77.

18 Hovingh GK, Kastelein JJ, van Deventer SJ, Round P, Ford J, Saleheen D, et al. Cholesterol ester transfer protein inhibition by TA8995 in patients with mild dyslipidaemia (TULIP): a randomised, double-blind, placebo-controlled phase 2 trial. Lancet. 2015 Aug; 386(9992):452-60.

19 Teramoto T, Takeuchi M, Morisaki Y, Ruotolo G, Krueger KA. Efficacy, safety, tolerability, and pharmacokinetic profile of evacetrapib administered as monotherapy or in combination with atorvastatin in Japanese patients with dyslipidemia. Am J Cardiol. 2014 Jun; 113(12):2021-9.

20 Li C, Zhang W, Zhou F, Chen C, Zhou L, Li $\mathrm{Y}$, et al. Cholesteryl ester transfer protein inhibitors in the treatment of dyslipidemia: a systematic review and meta-analysis. PLoS One. 2013 Oct;8(10):e77049.
21 Verdoia M, Schaffer A, Suryapranata H, De Luca G. Effects of HDL-modifiers on cardiovascular outcomes: a meta-analysis of randomized trials. Nutr Metab Cardiovasc Dis. 2015 Jan;25(1):9-23.

22 Bots ML, Visseren FL, Evans GW, Riley WA, Revkin $\mathrm{JH}$, Tegeler $\mathrm{CH}$, et al.; RADIANCE 2 Investigators. Torcetrapib and carotid intima-media thickness in mixed dyslipidaemia (RADIANCE 2 study): a randomised, doubleblind trial. Lancet. 2007 Jul;370(9582):15360.

23 Suico JG, Wang MD, Friedrich S, Cannady EA, Konkoy CS, Ruotolo G, et al. Effects of the cholesteryl ester transfer protein inhibitor evacetrapib on lipoproteins, apolipoproteins and 24-h ambulatory blood pressure in healthy adults. J Pharm Pharmacol. 2014 Nov; 66(11):1576-85.

24 Riaz H, Khan SU, Rahman H, Shah NP, Kaluski E, Lincoff AM, et al. Effects of highdensity lipoprotein targeting treatments on cardiovascular outcomes: A systematic review and meta-analysis. Eur J Prev Cardiol. 2019 Mar;26(5):533-43.

25 Singh IM, Shishehbor MH, Ansell BJ. Highdensity lipoprotein as a therapeutic target: a systematic review. JAMA. 2007 Aug;298(7): 786-98.

26 Gordon DJ, Probstfield JL, Garrison RJ, Neaton JD, Castelli WP, Knoke JD, et al. Highdensity lipoprotein cholesterol and cardiovascular disease. Four prospective American studies. Circulation. 1989 Jan;79(1):8-15.
27 Tall AR. An overview of reverse cholesterol transport. Eur Heart J. 1998;19 Suppl A: A31-5.

28 Fisher EA, Feig JE, Hewing B, Hazen SL, Smith JD. High-density lipoprotein function, dysfunction, and reverse cholesterol transport. Arterioscler Thromb Vasc Biol. 2012 Dec;32(12):2813-20.

29 Mohammadpour AH, Akhlaghi F. Future of cholesteryl ester transfer protein (CETP) inhibitors: a pharmacological perspective. Clin Pharmacokinet. 2013 Aug;52(8):615-26.

30 Armitage J, Holmes MV, Preiss D. Cholesteryl Ester Transfer Protein Inhibition for Preventing Cardiovascular Events: JACC Review Topic of the Week. J Am Coll Cardiol. 2019 Feb;73(4):477-87.

31 Gotto AM Jr, Cannon CP, Li XS, Vaidya S, Kher U, Brinton EA, et al.; DEFINE Investigators. Evaluation of lipids, drug concentration, and safety parameters following cessation of treatment with the cholesteryl ester transfer protein inhibitor anacetrapib in patients with or at high risk for coronary heart disease. Am J Cardiol. 2014 Jan;113(1):76-83.

32 Krishna R, Gheyas F, Liu Y, Hagen DR, Walker B, Chawla A, et al. Chronic Administration of Anacetrapib Is Associated With Accumulation in Adipose and Slow Elimination. Clin Pharmacol Ther. 2017 Nov;102(5):832-40.

33 Ference BA, Kastelein JJ, Ginsberg HN, Chapman MJ, Nicholls SJ, Ray KK, et al. Association of Genetic Variants Related to CETP Inhibitors and Statins With Lipoprotein Levels and Cardiovascular Risk. JAMA. 2017 Sep;318(10):947-56. 